Journal of Advanced College of Engineering and Management, Vol 6, 2021

\title{
ENERGY SECURITY ASSESSMENT OF NEPAL FOR THE PERIOD 2005-2030
}

\author{
Shova Darlamee ${ }^{1}$, Prof. Dr. Tri Ratna Bajracharya ${ }^{2}$ \\ ${ }^{1,2}$ Department of Mechanical Engineering, IOE, Pulchowk Campus, Pulchowk, Tribhuwan University, Nepal \\ shovadarlamee@gmail.com
}

\begin{abstract}
Energy is an important driver of all economic activities and it is necessary for the production of goods and the provision of services. Thus, a secure supply of energy to meet national demand on both the short term and long term is important for any country. As a net importer of petroleum products from only one supplier country of petroleum products (i.e. India), supply and demand gap of energy, frequent price fluctuations of petroleum products and poor diversification of primary energy supply, policies regarding energy security should be developed for Nepal. This study aims to assess the energy security index of Nepal so as to provide a picture of the historical performance of the country in terms of energy security for the past years 2005-2015 and in the future 2016-2030 under different scenarios. A set of 24 energy security indicators were selected based on literature review and relevant to national energy policies and grouped under 5 dimensions which are availability, affordability, accessibility, efficiency and acceptability. It can be seen that energy security for Nepal has been following a declining trade since 2005/06 to 2015/16, the causes of which could be attributed to the increase in energy consumption, increase in imports of petroleum products, increase in electricity deficit from the year 2008/09, increase in price of petroleum products. However, the value of energy security index is on the higher side (near to 10) which is mainly due to the fact that energy supply of Nepal is mostly dependent on traditional sources which is domestically supplied. There is a need to incorporate energy security in the national energy policy of Nepal with more emphasis on diversification of primary energy sources (other than traditional resources), reduction on import dependency especially on fossil fuel resources, strategic fuel reserves, diversification of energy resources uses in different energy consumption sectors like transport, industries, increase in energy supply from renewable energy sources, etc.
\end{abstract}

Keywords: Energy Security, Indicators, Normalization, weighing and aggregation, Principal Component Analysis, Energy Security Index, Shannon-Weiner Index, Net Energy Import Dependency, Energy model, Scenario Analysis, LEAP

\section{Background}

Historically, energy security concept focused on crude oil supply disruptions in the Middle East and studies on energy security was dominated by oil supply security only. In recent years, there have been various definitions of energy security suggested, some of which were created from international institutions; for example, the International Energy Agency defines energy security as "the uninterrupted availability of energy sources at an affordable price"[8]. Energy security as defined by [14] is the "technical feasibility, affordability, environmental protection, reliability and security of supply". There is no ideal definition of energy security. The meaning of energy security is highly context dependent, such as a country's special circumstances, level of economic development, perceptions of risks, as well as the robustness of its energy system and prevailing geopolitical issues. Chester[4]described the concept of energy security as 'polysemic' and 'slippery', referring to its tendency to symbolize multiple dimensions at the same time. There can also be different priorities and opportunities in industrialized and developing countries. In the latter case, energy security tends to be more closely connected to provision of energy access to the poorest in rural areas and, in urban areas, access for the rapidly expanding industry and service sectors [11].Energy is an important driver of all economic activities and it is necessary for the production of goods and the provision of services. Securing energy supply to meet national demand on both the short term and long term, is one of the most important priorities for any country overall the world, and some countries consider ensuring energy security as a national goal. Many countries consider energy security as equivalent to national security because of its influence on national autonomy and development goal. Energy security has 
been integrated into a major part of energy policy. It is generally accepted that energy security is strongly related to other policies as well, for example environmental and climate policies [12].

\section{Problem Statement}

Nepal's Energy Resources Are Broadly Divided Into Three Categories: Traditional, Commercial And Alternative. Traditional Sources Include Fuel wood, Agricultural Residues And Animal Wastes Whereas Energy Resources With Well-Established Market Prices Like Petroleum Products, Coal, And Grid Electricity Are Grouped Under Commercial Energy Sources And Indigenous Renewable Energy Sources Like Off-Grid Mini And Micro Hydro, Solar, Biogas, And Wind Come Under Alternative Energy Resources. Nepal's Energy Use Is Primarily Dominated By Traditional Sources Energy, Mainly Biomass For Domestic Purposes. Despite A Huge Potential For Renewable Energies Such As Hydropower, Solar Power And Wind Energy, These Resources Have Not Been Sustainably Captured Due To Geographical, Technical, Political And Economic Reasons. As A Result, The Country Is Facing Acute Power Shortage Of Electricity And Load Shedding. Nepal Is Totally Dependent In Terms Of Imports Of Petroleum Products For Its Energy Requirement [18]. An Oil Price Vulnerability Index (OPVI) Was Developed For 24 Asian And The Pacific Countries Based On The Macroeconomic Indicators, The Economic And Energy Variables [16] Where Nepal Was Classified As Highly Vulnerable Country.The Present Energy Consumption Pattern Is Unsustainable In Terms Of Resources And Economy As It Depends On Forests And Imported Petroleum Products. As A Net Importer Of Petroleum Products, Nepal Is Inevitably Vulnerable To Oil Supply Disruptions, Oil Price Fluctuations, And Geopolitical Dynamics Shaping The Energy Exporting Countries. The Continued Use Of Fossil Fuels In The Country Not Only Highlights The Issue Of Energy Security But Also The Equally Important Issue Of Sustainability. As A Net Importer Of Petroleum Products From Only One Supplier Country Of Petroleum Products (I.E. India), Supply And Demand Gap Of Energy, Frequent Price Fluctuations Of Petroleum Products And Poor Diversification Of Primary Energy Supply, Policies Regarding Energy Security Should Be Developed For Nepal. This Study Aims To Assess The Energy Security Index Of Nepal So As To Provide A Picture Of The Performance Of The Country In Terms Of Energy Security For The Past Years 2005-2015 And In The Future 2016-2030 Under Different Scenarios. The Period 2005-2015 For The Calculation Of Energy Security Index Is Selected To Evaluate The Trend Of Energy Security Situation In Nepal While The Period 2016-2030 Is Selected For Scenario Analysis To Evaluate The Change In Energy Security Index Of Nepal In Future Under Different Scenarios, Which Are Developed Based On The Sustainable Development Goals Of Nepal, 2015-2030 [13] And National Energy Crisis Reduction And Electricity Development Decade, 2016-2026.

\section{Methodology}

There are a large number of energy security indices which are available in literature, such as diversitybased index [9], Energy Security Index, ESI price and ESI volume [7], Energy Development Index [6], Energy Sustainability Index [5].All these studies use some form of weights and scores to create an index. There has been increasing interest in the quantification of energy security risk using indicators and indexes. Various studies have proposed a wide variety of energy security indexes, either to compare performance among countries or to track changes in a country's performance over time. In such studies, a workable definition of energy security suitable in the context of the study is selected, along with a set of appropriate energy security indicators identified based on some specific considerations or theoretical framework. Having framed the energy security definition and selected the appropriate indicators, the requisite data is collected and a composite energy security index is constructed following the three additional steps which are as below [2]: 
1. Normalizing the indicators: The selected indicators usually have different units and are on different scales. Transformation is needed before they can be aggregated to form a composite index. The common practice is through normalization using one of the following three methods: Min-max, distance to reference, and standardization.

2. Weighting the normalized indicators: The weights of the indicators can be assigned based on expert opinions or other subjective procedures. Different weighing methods have been applied in different studies, among which Equal Weighing is the most common method followed by Principal Component Analysis (Oil Vulnerability Index), relative fuel share (Supply-Demand Index), Analytical Hierarchy Process, expert judgment, etc.

3. Aggregating the normalized indicators: Aggregation involves combining the weighted indicators into a composite index. The simplest and most popular aggregation method is the additive aggregation method, where the indicators are first multiplied by the weights assigned and then summed to arrive at the index.

In this study, the selection of energy security definition and energy security indicators is solely based on exhaustive literature review. All the energy security indicators, both simple and complex type indicators, found in the literature till now were listed and analyzed thoroughly in order to be suitable to use in the context of Nepal. Since the main focus of energy studies and policies in Nepal are on the sustainability of energy system, Energy Indicators for Sustainable Development (EISD) developed by UNDP was also taken as reference. The normalization, weighing and aggregation methodology has been adopted from [11] where an "Aggregated Energy Security Performance Indicator" suitable for analysis of energy security at national and provincial level with time series data of indicators has been developed and used in finding AESPI of Thailand. AESPI uses weighting factor as it is based on principal component analysis (PCA) rather than expert judgments to increase the robustness of its results. The data for indicators for the year 2005-2015 were collected from secondary sources like national reports, international reports, etc. and for calculation of the indicators in future from year 2016-2030, an energy model is developed using LEAP (Long-range Energy Alternatives Planning) software and scenario analysis is carried out.

\section{Energy Security Indicators}

Energy security indicators should reflect the vulnerabilities of vital energy systems identified at the earlier stages of the assessment. They can be selected from those suggested in the abundant literature or designed specifically for the purpose of a particular assessment. Selection of indicators should be guided by how well they represent a particular risk or vulnerability of a vital energy system [3]. However, an indicator is rarely a direct measure of a risk or a resilience capacity. Rather it is a quantitative proxy, a signal of a state of a complex and dynamic energy system [2]. Energy security indicators has also been classified into two types which are disaggregated indicators (set of individual indicators) such as reserve to production ratio (RPR), strategic fuel stocks, Shannon-Wiener Index (SWI), Non-carbon intensive fuel portfolio (NCFP), energy import dependency (NEID), geopolitical market concentration risk (GMC), Market Liquidity (ML), Geopolitical Energy Security (GES), oil expenditure per GDP, final energy cost per GDP, etc. and aggregated indicators like "Oil vulnerability index (OVI)" based on oil market risk and oil supply risk, and uses 7 individual indicators, "Assessment Index (AI)" constructed from 46 energy and climate policy indicators. "Aggregated Energy Security Performance Indicator (AESPI)" was developed using 25 indicators to give a holistic performance of energy security relating social, economic and environment dimensions. AESPI has been used as baseline or benchmark of energy security for the Thailand as it can show the pathway of current policies/measures, trends (scenario) in the future, and also the pathway of alternate 
scenarios of new policies. Martchamadol [12] used "Aggregated Energy Security Performance Indicator (AESPI)" to assess Thailand's past and future energy security performance.

No single set of metrics is suitable for assessing energy security for all purposes in all situations. There is no particular set of indicators as energy security is context dependent and may vary from country to country. Also, there is no agreed value of the numbers of indicators to be used as there can be 5-6 indicators in less to about 320 indicators as well. The selection of energy security indicators for this study was solely by exhaustive literature review. All the energy security indicators, both simple and complex type indicators, found in the literature till now were listed and analyzed one by one in order to be suitable to use in the context of Nepal. Since the main focus of energy studies and policies in Nepal are on the sustainability of energy system, Energy Indicators for Sustainable Development (EISD) developed by UNDP was also taken as reference.

The indicators selected in this study for the assessment of energy security of Nepal are as below:

1. Availability dimension

- Diversity of Primary Energy Sources, Shannon- Weiner Index

- $\quad$ Net Energy Import Dependency

- $\quad$ Net Oil Import Dependency

- $\quad$ Strategic Fuel Stock as number of days of stock of petroleum products

- $\quad$ Self Sufficiency or Share of domestic production of primary energy

- $\quad$ Annual electricity deficit

- Total Final Energy Consumption per capita

- $\quad$ Electricity Consumption per capita

- $\quad$ Oil Consumption per capita

- Value of oil imports per unit of GDP

- $\quad$ Average annual price of electricity

- $\quad$ Average annual price of petroleum products

$\begin{array}{ll}\text { 2. } & \text { Affordability dimension } \\ \text { 3. } & \text { Accessibility dimension } \\ \text { - } & \text { Access to electricity } \\ \text { - } & \text { Access to modern cooking fuel } \\ \text { 4. } & \text { Efficiency dimension } \\ \text { - } & \text { Final Energy Intensity } \\ \text { - } & \text { Residential Energy Intensity } \\ \text { - } & \text { Industrial Energy Intensity } \\ \text { - } & \text { Commercial Energy Intensity } \\ \text { - } & \text { Oil Consumption per unit of GDP } \\ \text { - } & \text { Electricity Transmission and } \\ & \text { Distribution losses } \\ \text { 5. } & \text { Acceptability dimension } \\ \text { - } & \text { Non carbon fuel portfolio } \\ \text { - } & \text { Annual } \mathrm{CO}_{2} \text { emissions per capita }\end{array}$

\section{Construction of energy security index for Nepal for the period 2005-2015}

After selection of indicators and collection of related data, indicators were calculated using the appropriate formula. Then, the energy security indicators were normalized in the scale of 0 to 10,10 being the highest value implying highest energy security performance and 0 being the lowest value implying the worst energy security conditions. The indicators need to be classified as positive type and negative type before normalizing. Positive indicators like Shannon-Weiner diversification index [16], non-carbon fuel portfolio, etc. mean indicators with positive impact on energy security such that higher the value of the indicator better the energy security conditions whereas negative indicators like electricity deficit, economic vulnerability, etc. mean indicators with negative impact such that higher the value of the negative indicator, lower the energy security. The indicators were normalized using a scaling technique as below: 


$$
\operatorname{Max}_{\mathrm{i}}=\operatorname{Max}\left\{\mathrm{X}_{\mathrm{ij}, \ldots \ldots,} \mathrm{X}_{\mathrm{in}}\right\}
$$

$$
\emptyset_{i j}=\frac{10 \times X_{i j}}{\operatorname{Max}_{i}}
$$

Where, $\square_{\mathrm{ij}}$ is relative indicator $\mathrm{i}$ of year $\mathrm{j}$,

$\mathrm{Xij}$ is value of positive indicator $\mathrm{i}$ of year $\mathrm{j}$,

$\mathrm{Max}_{i}$ is the maximum value of indicator $\mathrm{i}$, and

$i$ is indicator $i$

For normalization of the negative indicators, the inverse of the indicators (Yij) were taken in the above formula.:

$$
Y_{i j}=\frac{1}{X_{i j}}
$$

The standardized indicators need to pass the test of sampling adequacy and correlation testing by Kaiser- Meyer-Olkin (KMO) and Bartlett's test for suitability of principal component analysis method. In KMO test, if $0.5<\mathrm{KMO}<1$, the time series data is suitable for analysis by PCA. The value of Overall MSA obtained from the KMO test is 0.5 which is below 0.8 which is the most favorable value, however the value of Overall MSA of 0.5 shows that the sample indicators are adequate for PCA method. Similarly, from the Bartlett's test of sphericity, the significance level of chi-square results lower than 0.05 (confidential level 95\%, a $=0.05$ ) means these indicators are correlated with each other (or correlation matrix is not identity matrix). So, these indicators are suitable for analysis by PCA method. R-studio software was used for PCA in this study.PCA involves finding the eigenvalues of the sample covariance matrix CM. After standardization of the variables, the covariance matrix $C M$ then takes the form of the correlation matrix, $\mathrm{R}(\mathrm{N} \times \mathrm{N}), \mathrm{N}$ is the number of indicators. The eigenvalues of the correlation matrix by using following equation,

$$
R-\lambda I=0
$$

Where, 'R' is the correlation matrix, ' $\square$ ' is the eigenvalues, and'I' is the identity matrix.

Then, $\lambda$ is solved by $\mathrm{Nth}$ degree polynomial equation and therefore, $\mathrm{N}$ eigenvalues which correspond to the correlation matrix R are obtained. Finally, the number of groups of indicators can be identified by considering the eigenvalue that are higher than one [12].After PCA analysis, it was found that all the indicators could be grouped under one principal component. Thus, an equal weighing factor was given to each of the indicators and the energy security index of Nepal for the year 2005/06-2015/16 was calculated.

\section{Findings}

A. Indicator Formulation: Some of the indicators calculated are as below:

\section{- Diversity of Primary Energy Sources (Shannon-Weiner Index)}

Diversity in energy (fuel) type and geographical source is thought to be an important means to hedge against supply risks[1] and diversity amongst suppliers a means of hedging against market power [8].The Diversity of Fuel mix is given by Shannon-Weiner Index, calculated as below:

$$
D=\sum\left(p_{i} \ln p_{i}\right)
$$

Where D = Shannon's Diversity Index

$\mathrm{P}_{\mathrm{i}}=$ share of PES I in TPES 
The index has been calculated for Nepal for the period 2005/06-2015/16 considering fuel mix as coal, petroleum products, electricity, biomass and alternatives as below:

\begin{tabular}{|l|r|}
\hline Year & SWI, $-\left(\mathrm{p}_{\mathrm{i}} \ln \mathrm{p}_{\mathrm{i}}\right)$ \\
\hline $2005 / 06$ & 0.52048 \\
\hline $2006 / 07$ & 0.490629 \\
\hline $2007 / 08$ & 0.497035 \\
\hline $2008 / 09$ & 0.515524 \\
\hline $2009 / 10$ & 0.593383 \\
\hline $2010 / 11$ & 0.572627 \\
\hline $2011 / 12$ & 0.718755 \\
\hline $2012 / 13$ & 0.736691 \\
\hline $2013 / 14$ & 0.734063 \\
\hline $2014 / 15$ & 0.79143 \\
\hline $2015 / 16$ & 0.786281 \\
\hline
\end{tabular}

Table 1: Shannon-Weiner Index for primary energy supply of Nepal from 2005-2015

The Shannon-Weiner index is calculated by using the share of different primary energy resources in the primary energy supply of a country. Higher value of the index represents more diversified primary energy fuel mix, which helps strengthen the energy security conditions of a country. As seen from the table above, the diversity index value of Nepal is increasing, but insignificantly.

\section{- $\quad$ Net Energy Import Dependency}

Nepal is a net energy importer, particularly petroleum products, which makes the country highly vulnerable to oil supply disruptions, price hikes, embargos, etc. Coal, petroleum products and electricity are the energy sources imported by Nepal mostly from India. NEID is calculated by using the modified Shannon-Weiner Index; taking the share of energy sources $p_{i}$ in primary energy supply and share of imports of energy sources $\mathrm{m}_{\mathrm{i}}$.

\begin{tabular}{|l|r|r|}
\hline Year & $\left(\mathrm{m}_{\mathrm{i}} \mathrm{p}_{\mathrm{i}} \ln \mathrm{p}_{\mathrm{i}}\right)$ & \multicolumn{1}{l|}{ NEID } \\
\hline $2005 / 06$ & 0.3038 & $58.36 \%$ \\
\hline $2006 / 07$ & 0.2786 & $56.79 \%$ \\
\hline $2007 / 08$ & 0.2841 & $57.16 \%$ \\
\hline $2008 / 09$ & 0.2929 & $56.82 \%$ \\
\hline $2009 / 10$ & 0.3493 & $58.87 \%$ \\
\hline $2010 / 11$ & 0.3300 & $57.62 \%$ \\
\hline $2011 / 12$ & 0.4105 & $57.11 \%$ \\
\hline $2012 / 13$ & 0.4001 & $54.32 \%$ \\
\hline $2013 / 14$ & 0.3750 & $51.08 \%$ \\
\hline $2014 / 15$ & 0.4221 & $53.34 \%$ \\
\hline $2015 / 16$ & 0.4243 & $53.96 \%$ \\
\hline
\end{tabular}

Table 2: Net Energy Import Dependency of Nepal from 2005-2015 
It can be seen that the Net Energy Import Dependency of Nepal is on the higher side and has remained almost similar for the analysis period with slight decrease in recent years, which may be explained due to the increase in domestic production from mostly hydro and renewables. However, the country is still dependent on energy imports. The increment in years 2014/15 and 2015/16 is accountable to the increase in electricity imports.

\section{- $\quad$ Net Oil Import Dependency}

Nepal is totally dependent on oil or petroleum products imports from India. The Net Oil Import Dependency of Nepal is as below:

\begin{tabular}{|l|r|}
\hline Year & \multicolumn{1}{l|}{ NOID } \\
\hline $2005 / 06$ & $7.767 \%$ \\
\hline $2006 / 07$ & $7.910 \%$ \\
\hline $2007 / 08$ & $7.187 \%$ \\
\hline $2008 / 09$ & $8.243 \%$ \\
\hline $2009 / 10$ & $9.724 \%$ \\
\hline $2010 / 11$ & $8.203 \%$ \\
\hline $2011 / 12$ & $12.265 \%$ \\
\hline $2012 / 13$ & $11.084 \%$ \\
\hline $2013 / 14$ & $11.253 \%$ \\
\hline $2014 / 15$ & $12.527 \%$ \\
\hline $2015 / 16$ & $10.837 \%$ \\
\hline
\end{tabular}

Table 3: Net Oil Import Dependency of Nepal from 2005-2015

It can be seen that Net Oil Import Dependency of Nepal is increasing gradually, the slight decrease in the year 2015/16 can be attributed to the undeclared blockade by India, which created a crisis of petroleum products in the country.

- $\quad$ Number of days of stocks of petroleum products, AVL4

\begin{tabular}{|l|r|r|r|r|}
\hline \multicolumn{1}{|c|}{ Year } & \multicolumn{1}{|c|}{$\begin{array}{c}\text { Annual Sales } \\
\text { KL }\end{array}$} & $\begin{array}{c}\text { Sales per day } \\
\text { KL }\end{array}$ & $\begin{array}{c}\text { Storage } \\
\text { Capacity, full } \\
\text { capacity KL }\end{array}$ & Days cover \\
\hline $2005 / 06$ & 670275 & 1836.370 & 71674 & 39 \\
\hline $2006 / 07$ & 674964 & 1849.216 & 71674 & 39 \\
\hline $2007 / 08$ & 630927 & 1728.567 & 71674 & 41 \\
\hline $2008 / 09$ & 732239 & 2006.134 & 71674 & 29 \\
\hline $2009 / 10$ & 916026 & 2509.660 & 71674 & 26 \\
\hline $2010 / 11$ & 995220 & 2726.630 & 71674 & 26 \\
\hline $2011 / 12$ & 1000313 & 2740.584 & 71674 & 24 \\
\hline $2012 / 13$ & 1081638 & 2963.392 & 71674 & 26 \\
\hline
\end{tabular}




\begin{tabular}{|l|l|l|l|l|}
\hline $2013 / 14$ & 1207314 & 3307.710 & 71674 & 22 \\
\hline $2014 / 15$ & 1343875 & 3681.849 & 71674 & 19 \\
\hline $2015 / 16$ & 1116083 & 3057.762 & 71674 & 23 \\
\hline $2016 / 17$ & 1883138 & 5159.282 & 71674 & 14 \\
\hline $2017 / 18$ & 2299001 & 6298.633 & 71674 & 11 \\
\hline
\end{tabular}

The Strategic Petroleum Reserve is an effective way of minimizing the effect of supply crisis or blockades. The storage capacity of petroleum products of a country should be around 90 days as stated by IEA.

The above table shows that the storage capacity has not been increased and while the consumption or sales of petroleum products is increasing rapidly, the days covered by the available storage capacity is decreasing, and is just 11 days for the year 2017/18 which is very less compared to the ideal value of 90 days. The above days only accounts for the storage of petroleum products. In case of LPG, only some private suppliers have few storage capacities. There is no national level storage facility for LPG in Nepal.

- Annual electricity deficit

\begin{tabular}{|l|l|l|l|l|}
\hline Year & $\begin{array}{l}\text { Supply, } \\
\text { GWh }\end{array}$ & $\begin{array}{l}\text { Demand, } \\
\text { GWh }\end{array}$ & Deficit/Surplus & $\begin{array}{l}\text { \% } \\
\text { deficit }\end{array}$ \\
\hline $2005 / 06$ & & & & \\
\hline $2006 / 07$ & & & & \\
\hline $2007 / 08$ & 3052 & 3000 & 52 & \\
\hline
\end{tabular}

Table 4: Strategic Petroleum Reserves of Nepal from 2005-2015

\begin{tabular}{|l|r|r|r|r|}
\hline $2008 / 09$ & 3185 & 3490 & -305 & $-9 \%$ \\
\hline $2009 / 10$ & 3131 & 3859 & -728 & $-19 \%$ \\
\hline $2010 / 11$ & 3352 & 4367 & -1015 & $-23 \%$ \\
\hline $2011 / 12$ & 3858 & 4833 & -975 & $-20 \%$ \\
\hline $2012 / 13$ & 4179 & 5195 & -1016 & $-20 \%$ \\
\hline $2013 / 14$ & 4258 & 5446 & -1188 & $-22 \%$ \\
\hline $2014 / 15$ & 4687 & 5909 & -1222 & $-21 \%$ \\
\hline $2015 / 16$ & 5006 & 6335 & -1329 & $-21 \%$ \\
\hline
\end{tabular}

Table 5: Annual electricity deficit of Nepal from 2005-2015

Electricity supply shortage has been evident in Nepal since 2008/09 in the form of long hours of load shedding, resulting upto $14 \mathrm{hrs}$ a day in the dry season. The table above shows that the electricity deficit has been increasing for the analysis period. 
- Value of petroleum products imports per unit of GDP

\begin{tabular}{|c|c|c|c|}
\hline Year & $\begin{array}{c}\text { GDP (billion NRs. at } \\
2000 / 01 \text { price) }\end{array}$ & $\begin{array}{c}\text { Value of petroleum products } \\
\text { imports billion NRs }\end{array}$ & $\begin{array}{c}\text { Value of petroleum } \\
\text { products imports per unit } \\
\text { GDP }\end{array}$ \\
\hline $2005 / 06$ & 514.49 & 33.66 & 0.06542 \\
\hline $2006 / 07$ & 531.68 & 33.57 & 0.06314 \\
\hline $2007 / 08$ & 564.5 & 43.4448 & 0.07696 \\
\hline $2008 / 09$ & 590.1 & 43.7443 & 0.07413 \\
\hline $2009 / 10$ & 618.5 & 56.991 & 0.09214 \\
\hline $2010 / 11$ & 639.694 & 75.859 & 0.11859 \\
\hline $2011 / 12$ & 670.3 & 97.13 & 0.14491 \\
\hline $2012 / 13$ & 698 & 112.372 & 0.16099 \\
\hline $2013 / 14$ & 739.8 & 138.934 & 0.1878 \\
\hline $2014 / 15$ & 764.336 & 115.687 & 0.15136 \\
\hline $2015 / 16$ & 768.835 & 71.3892 & 0.09285 \\
\hline
\end{tabular}

Table 6: Value of petroleum products import from 2005-2015

The value of energy imports to GDP reflects economic vulnerability, to oil price shocks. Higher the value of energy imports to GDP higher is the vulnerability. It can be seen that the value of energy imports per unit of GDP of Nepal is increasing and the highest is in the year 2013/14. The decrease in the year 2015/16 is due to the decrease in the import of petroleum products. The expenditure made on petroleum products exceeded the value earned from exports from the year 2009/10, which is not preferable for the economic health of the country.

- $\quad$ Average Annual Price of Petroleum Products, AFF3

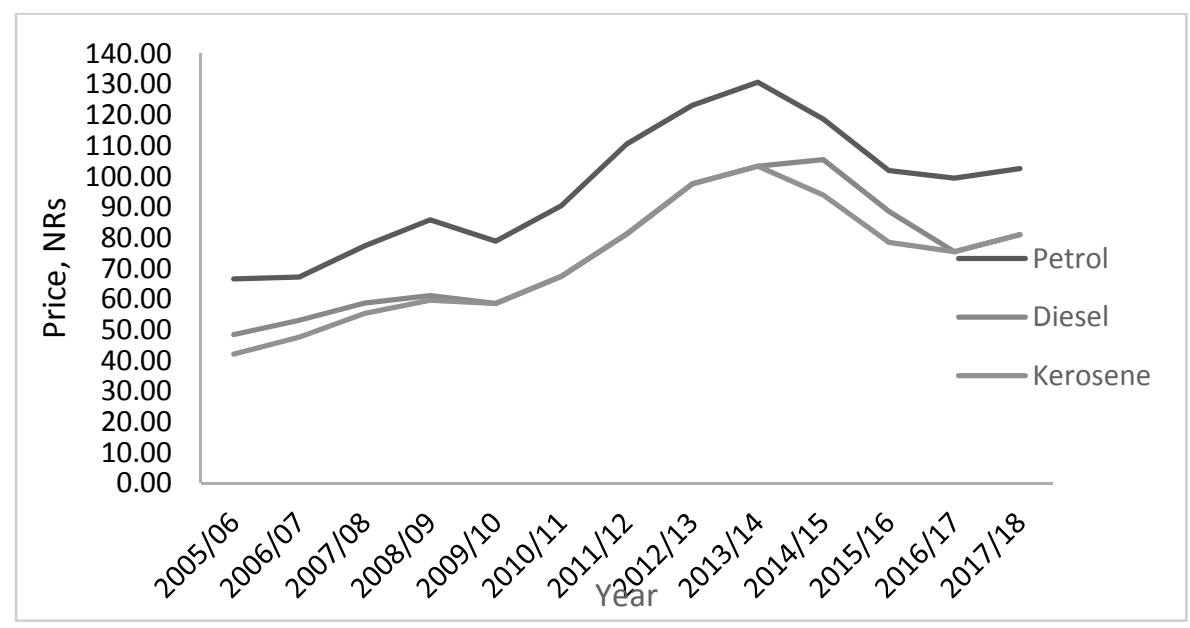

Fig 1: Average Annual Price of Petrol (NRs/Lt), Diesel (NRs/Lt) and Kerosene (NRs/Lt)

The annual price of petroleum products represents the volatility of petroleum product prices which reflects the energy security situations. Highly volatile price is degrading to energy security of any country. The annual prices of main petroleum products i.e. petrol, diesel, kerosene and LPG were 
calculated by taking average of daily prices in the year 2005/06-2015/16. The average annual price of petroleum products followed an increasing trend. The price of kerosene was increased in order to discourage kerosene as cooking fuel as well as to discourage the mixing of kerosene in motor fuels that degraded the quality of petrol. The petroleum products price has very high volatility.

- Non-Carbon Fuel Portfolio, ACP1

\begin{tabular}{|l|r|}
\hline \multicolumn{1}{|c|}{ Year } & NCFP $=\frac{\text { (Hydro PES }+ \text { Ren PES })}{\text { Total PES }}$ \\
\hline $2005 / 06$ & $2.244 \%$ \\
\hline $2006 / 07$ & $2.328 \%$ \\
\hline $2007 / 08$ & $2.391 \%$ \\
\hline $2008 / 09$ & $2.436 \%$ \\
\hline $2009 / 10$ & $2.437 \%$ \\
\hline $2010 / 11$ & $2.482 \%$ \\
\hline $2011 / 12$ & $3.274 \%$ \\
\hline $2012 / 13$ & $4.199 \%$ \\
\hline $2013 / 14$ & $5.112 \%$ \\
\hline $2014 / 15$ & $4.876 \%$ \\
\hline $2015 / 16$ & $4.898 \%$ \\
\hline
\end{tabular}

Table 7: Non-carbon fuel portfolio of Nepal from 2005-2015

Non-Carbon Fuel Portfolio gives the measure of contribution of non-carbon emitting energy sources like hydro, nuclear and renewables in the primary energy fuel mix of a country, which is better in terms of environmental sustainability. The Non-Carbon Fuel Portfolio of Nepal is improving with years.

\section{B. Energy Security Index}

After selection of indicators, data collection and formulation of indicators, the energy security index of Nepal was calculated using the above-mentioned normalization, weighing and aggregation method. The value of the calculated energy security index of Nepal from 2005-2015 can be illustrated as below: 


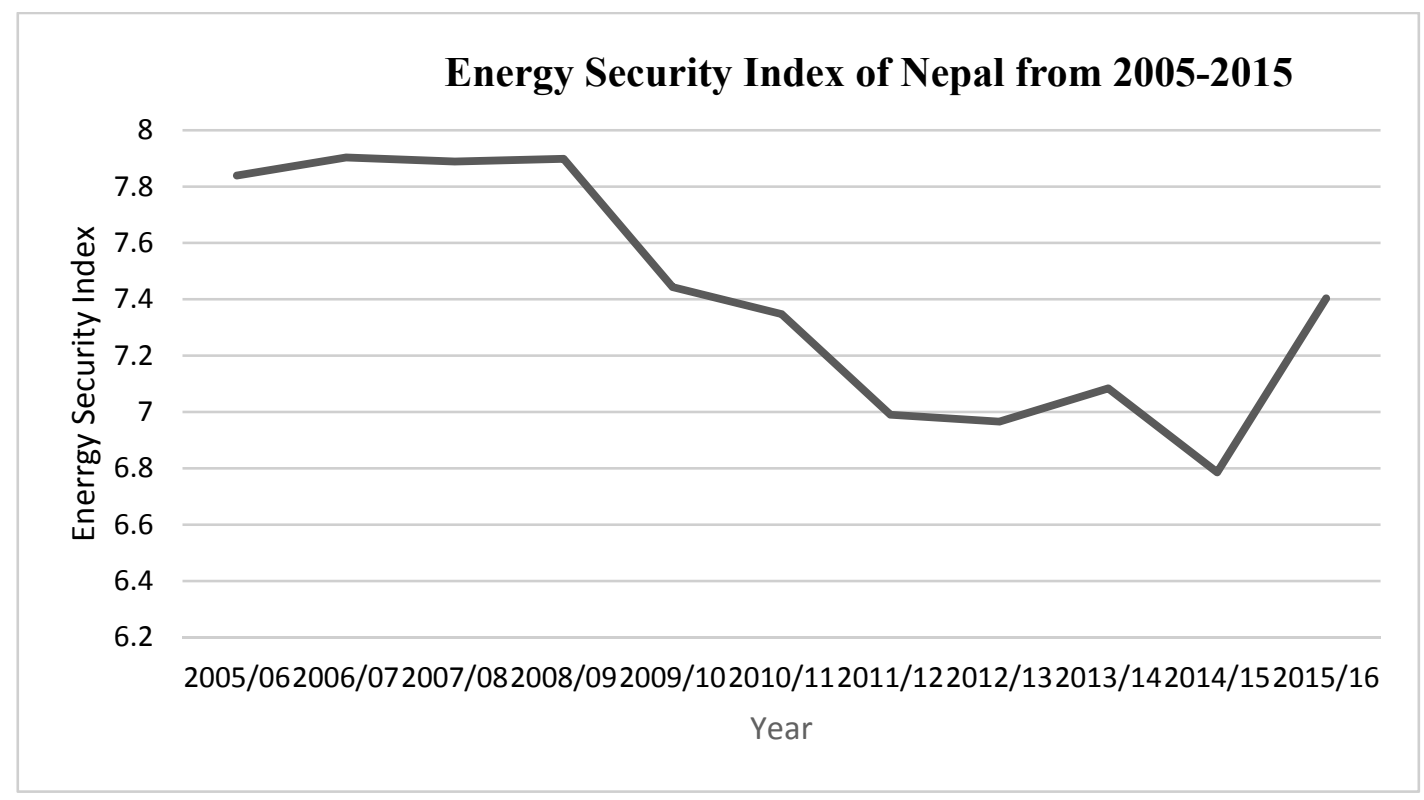

Fig 2: Energy Security Index of Nepal from 2005-2015

It can be seen that energy security for Nepal has been following a declining trade since 2005/06 to $2015 / 16$, the causes of which could be attributed to the increase in energy consumption, increase in imports of petroleum products, increase in electricity deficit from the year 2008/09, increase in price of petroleum products. However, the value of energy security index is on the higher side (near to 10) which is mainly due to the fact that energy supply of Nepal is mostly dependent on traditional sources which is domestically supplied. The energy security index is seen to be the least at 2014/15.

\section{Conclusions}

Energy Security is highly context dependent, complex and dynamic in nature, nonetheless it is one of the most important factors in development of energy related policies in many countries. In the context of Nepal, it can be seen that Nepal still relies heavily on traditional energy sources which develops the issue of sustainability. The study shows that apart from traditional energy sources, the diversity in fuel mix is very low and it has not yet been improved in the period of 10 years from 2005-2015. Nepal is fully dependent on imported fossil-fuel based energy sources, and electricity as well, which has made the country vulnerable to supply disruptions and price shocks. Nepal spends huge amount of money in imports of petroleum products from India. The high value of energy imports to GDP reflects high economic vulnerability to oil price shocks. It can be seen that the value of energy imports per unit of GDP of Nepal is increasing and the highest is in the year 2013/14. Similarly, the strategic petroleum reserve of Nepal that can act against short term supply disruptions is declining and is just up to 11 days in the year 2015/16 which is very low compared to the standard of 90 days. The expenditure made on petroleum products exceeded the value earned from exports from the year 2009/10, which is not preferable for the economic health of the country. On the electricity sector, Nepal faced electricity deficit throughout the period of 2005-2015, while it imported electricity in the years 2014/15 and 2015/16 that increased the import dependency of Nepal. Thus, the study shows that the energy security situation of Nepal is degrading from the year $2005 / 06$ to $2015 / 16$. While the country is progressing in terms of development of alternative renewable energy sources, there is still a lot to achieve to strengthen the energy security aspect of Nepal. The calculated energy security index can be useful in benchmarking and tracking the progress of energy security situation of Nepal in the upcoming years. 


\section{Recommendations}

There is a need to incorporate energy security in the national energy policy of Nepal with more emphasis on diversification of primary energy sources (other than traditional resources), reduction on import dependency especially on fossil fuel resources, strategic fuel reserves, diversification of energy resources uses in different energy consumption sectors like transport, industries, increase in energy supply from renewable energy sources, etc.

\section{Limitations}

As energy security is highly context-dependent, the energy security assessment framework, selection of indicators and composition of index can vary from country to country, thus the calculated energy security index of Nepal is not applicable for cross-comparison with other countries. Since, an indicator is not always a direct measure of a risk or a resilience capacity but can be viewed as a proxy, this study does not define what scores indicate energy security or energy insecurity. Rather, the energy security index simply reflects changes in Nepal's energy security status with time, indicating whether the situation has improved or deteriorated. The scope of the study is limited by the availability of data. The data used for the study are taken from secondary sources by doing the necessary extrapolations and deductions whenever required. 


\section{References}

1 Asia Pacific Energy Research Centre (APERC), 2007. A Quest for Energy Security inthe2 $1^{\text {st }}$ century; Institute of energy economics, Japan.

2 B.W. Ang, W. C. (2015). Energy security: Definitions, dimensions and indexes. Renewable and Sustainable Energy Reviews 42, 1077-1093.

3 Cherp, A., \& Jewell, J. (2011a). Measuring energy security: from universal indicators to contexualized frameworks. The Routledge Handbook of Energy, 330-355.

4 Chester, L. (2010). Conceptualising energy security and making explicit its polysemic nature.Energy Policy, 38(2), 887-895.

5 Doukas, H., Papadopoulou, A., Savvakis, N., Tsoutsos, T., \& Psarras, J. (2012). Assessing energy sustainability of rural communities using principal component analysis. Renew Sustain Energy Rev , 1949-1957.

6 IEA (International Energy Agency). (2010). World energy outlook.Paris.

7 IEA. (2007a). Energy security and climate change assessing interactions. International Energy Agency. Paris.

8 IEA. (2007b). Contribution of renewables to energy security. International Energy Agency. Paris.

9 Jansen, J., Arkel, V., \& Boots, M. (2004). Designing indicators of long-term energy supply security.

10 Kruyt, B., Vuuren, D., Vries, H., \& Groenenberg, H. (2009). Indicators for energy security. Energy Policy, 2166-2181.

11 Kuik, O., Lima, M., \& Gupta, J. (2011). Energy security in a developing world.Wiley Interdiscip Rev Clim Change, 2(4), 627-634.

12 Martchamadol, J., \& Kumar, S. (2012). Thailand's energy security indicators. Renew Sustain Energy Rev 2012, 103-122.

13 National Planning Commission. (2015). Sustainable Development Goals 2016-2030, National (Preliminary) Report.National Planning Commission, Government of Nepal.

14 Phdungsilp, A. (2010). Assessing energy security performance in Thailand under different scenarios and policy implications. Energy Procedia 79, 982-987.

15 Sovacool, B. K., \& Mukherjee, I. (2011). Conceptualizing and measuring energy security: A synthesized approach.Energy, 36, 5343-5355.

16 UN. (2007). Assessing policy options for increasing the use of renewable energy for sustainable. UN Headquarters, New York, USA.

17 Vivoda, V. (2009). Diversification of oil import sources and energy security: a key strategy or elusive objective. Energy Policy , 4615-4623.

18 WECS. (2013). National Energy Strategy of Nepal.Kathmandu: Water and Energy Commission Secretariat, GoN. 